\title{
TERMOGRAFIJA I ENERGETSKA UČINKOVITOST STAMBENIH OBJEKATA
}

\author{
Rijad Šišić \\ Rudarsko-geološko-građevinski fakultet Tuzla, Univerzitetska 2, Tuzla, docent \\ Amela Hodžić \\ Rudarsko-geološko-građevinski fakultet Tuzla, student dodiplomskog studija \\ Adi Kevilj \\ Rudarsko-geološko-građevinski fakultet Tuzla, student dodiplomskog studija \\ Omer Hrustić \\ Rudarsko-geološko-građevinski fakultet Tuzla, student dodiplomskog studija
}

Sažetak: Najveći dio ukupno utrošene energije u prosječnim stambenim objektima otpada na ostvarivanje toplinskog komfora. Kod stariji objekata bez toplinske izolacije na vanjskim zidovima, odnosno kod objekata s neadekvatnom konstrukcijom i toplinskom izolacijom, toplinski gubitci su evidentni i neizbježni. Infracrvena termografija pokazala se kao izuzetno uspješna i jednostavna metoda za otkrivanje toplinskih gubitaka kroz elemete konstrukcije. Interpretacijom rezultata moguće je, bez destrukcije, uočiti konstrukcijske i izolacijske nedostatke, te njihovim otklanjanjem povećati energetsku učinkovitost objekata. U radu je korištena IC kamera FLIR i7.

Ključne riječi: infracrvena termografija, energetska učinkovitost, toplinski gubitci

\section{THERMOGRAPHY AND ENERGY EFFICIENCY OF DWELLING STRUCTURES}

Abstract: Major part of energy in conventional dwelling structures is used for space heating. At older dwelling structures with no heating insulation at outer walls, as well as structures with inadequate construction and heating insulation, heat losses are evident and unavoidable. Infra red thermography proved as a very powerful, successful and simple method for detecting heat losses through construction elements. It is possible to detect structural and insulation failings based on results interpretations without destruction, and thus to increase energy efficiency of structures by removing the failings. The paper gives an overview of IC thermography potential for detecting heat losses and for assessing energy efficiency of dwelling structures proven on several cases using FLIR i7 IC camera.

Key words: Infra red thermography, energy efficiency, heat losses 


\section{Uvod}

\subsection{Infracrvena termografija}

Infracrvena termografija, termalno snimanje, termografsko snimanje, ili termalni video, podvrsta je područja infracrvenog snimanja, a temelji se na opažanju intenziteta toplinskog zračenja i trajnom zapisivanju u odgovarajućem obliku, tako da između instrumenta i predmeta mjerenja nema direktnog kontakta. Količina toplinske energije koja se emitira s površine direktno je proporcionalna temperaturi površine [1]:

gdje je:

$$
E=\varepsilon \cdot \sigma \cdot T^{4}
$$

$\mathrm{E}$ - emitirana energija [J]

$\varepsilon-$ koeficijent emisivnosti

$\sigma-$ Stefan-Boltzmanova konstanta

$\mathrm{T}$ - temperatura tijela $[\mathrm{K}]$.

Termografske kamere opažaju zračenje u infracrvenom pojasu elektromagnetskog spektra (u granicama od približno 0,9-14 mikrometara). Kako infracrveno zračenje emitiraju sva tijela ovisno o njihovoj temperaturi, prema zakonu zračenja crnog tijela, termografija omogućava "gledanje“ okoline bez vidljivog osvjetljenja. Gledani termografskom kamerom, topli predmeti se dobro ističu u odnosu na hladniju pozadinu; ljudi i toplokrvne životinje postaju lako vidljivi u odnosu na okoliš, danju i noću (slika 1). S toga ne čudi da se široka uporaba termografije povijesno veže uz vojsku i uz službe osiguranja.

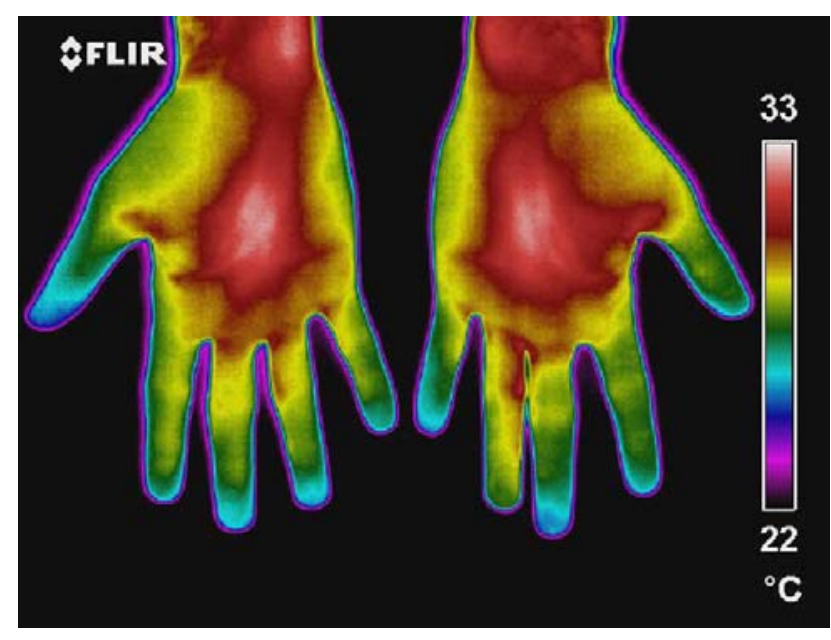

Slika 1 - Termogram dlanova u infracrvenom pojasu

[izvor: http://www.rsdconsultants.com/Thermography.htm]

IC termografija, pored niza uočenih prednosti i mogućnosti primjene u drugim područjima ljudske djelatnosti (medicina, zaštita, sigurnost itd.), danas se pokazuje kao izuzetno korisna metoda u istraživanju i unaprjeđivanju energetske učinkovitosti u zgradarstvu.

\subsection{Energetska učinkovitost u građevinarstvu}

Pod pojmom unapjređenja energetske učinkovitosti u zgradarstvu podrazumijeva se kontinuirani i široki opseg djelatnosti kojima je krajnji cilj smanjenje potrošnje svih vrsta energije uz jednake ili bolje uvjete u objektu. Posljedica smanjenja neobnovljivih izvora energije (fosilna goriva) i korištenje obnovljivih je smanjenje emisija stakleničnih plinova $\left(\mathrm{CO}_{2} \mathrm{i} \mathrm{dr}\right.$.), što doprinosi zaštiti prirodnog okoliša, smanjenju globalnog zagrijavanja i održivom razvoju zemlje [2]. 
Energetska učinkovitost pokriva izrazito široko područje, od građevinarstva i prometa do distribucije energije i pitke vode, odnosno od domaćinstva do javnih zgrada i industrije. Zgrade su najveći pojedinačni potrošač energije (tabela 1) i veliki izvor štetnih emisija stakleničnih plinova, posebno $\mathrm{CO}_{2}$. Povećanje energetske učinkovitosti u zgradama jedan je od najisplativijih načina smanjenja štetnih emisija u okoliš, kao i smanjenja troškova za energiju.Više od $80 \%$ zgrada u BiH nema odgovarajuću toplinsku zaštitu, kao ni odgovarajući sustav grijanja i hlađenja [3]. U sljedećoj tabeli, preuzetoj iz Studije energetskog sektora u BiH koju je izradio Institut Hrvoje Požar iz Zagreba, prikazana je potrošnja energije u našoj zemlji po sektorima [4].

\section{Tabela 1 - Potrošnja energije po sektorima u Bosni i Hercegovini}

\begin{tabular}{|c|c|c|c|c|c|c|c|c|}
\hline & 1990 & 2000 & 2001 & 2002 & 2003 & 2004 & 2005 \\
\cline { 2 - 8 } & \multicolumn{7}{|c|}{ PJ } \\
\hline Industrija & 92,25 & 27,84 & 25,41 & 23,93 & 23,7 & 29,96 & 34,45 \\
\hline Transport & 32,46 & 28,34 & 27,58 & 25,47 & 26,78 & 29,66 & 29,27 \\
\hline Kućanstva & 83,89 & 67,39 & 71,44 & 68,68 & 73,52 & 72,84 & 79,57 \\
\hline Usluge & 10,04 & 8,09 & 8,44 & 8,75 & 8,75 & 9,06 & 9,7 \\
\hline Poljoprivreda & 5,72 & 2,94 & 2,82 & 2,71 & 2,8 & 3,23 & 3,15 \\
\hline Ukupno: & 224,36 & 134,6 & 135,69 & 129,54 & 135,55 & 144,75 & 156,14 \\
\hline
\end{tabular}

Izloženi podatci pokazuju da se približno $50 \%$ od ukupne potrošnje energije odnosi na sektor kućanstava. Čak više od 60 \% ukupne količine energije koja se troši u kućanstvima, troši se za zagrijavanje prostora. Do ovako velike potrošnje dolazi najviše zbog velikih gubitaka topline zbog loše ili nikakve izolacije vanjskih zidova, velikih gubitaka topline kroz nekvalitetne prozore, zbog neodgovarajuće izolacije podova i stropova, te vrlo zastarjelih sustava grijanja. Od iznimne je važnosti obratiti pozornost ovom sektoru, jer se ovdje nalaze i najveći potencijali za uštede. Suvremena arhitektura i gradnja danas uključuje mjere energetske učinkovitosti sustava vanjske ovojnice, te sustava grijanja, ventilacije, klimatizacije i rasvjete, nadzor i upravljanje energetikom zgrade, te razmatra mogućnosti korištenja obnovljivih izvora energije u zgradama [3].

\section{Prednosti i i ograničenja termografije}

Kao i svaka tehnologija, IC termografija ima svoje prednosti i nedostatke $[5,6]$ :

- Prikazuje vidljivu sliku tako da se mogu usporediti temperature na velikoj površini

- Beskontaktno mjerenje

- Sposobna je fokusirati i snimiti mete u kretanju u realnom vremenu

- $\quad$ Može se koristiti za mjerenja nepristupačnih i opasnih mjesta

- Može se koristiti za detekciju defekata u metalnim dijelovima i konstrukcijama

- Može se koristiti za poboljšanje moći opažanja u mračnim područjima.

Ograničenja i mane termografije su:

- Termalne kamere su skupe

- Snimci se teško interpretiraju kad se radi o objektima s nehomogenim temperaturama

- Precizna mjerenja ometa nejednolika emisivnost i refleksije od drugih površina

- Većina kamera ima $\pm 2 \%$ preciznosti ili gore, i nisu precizne kao kontaktne metode

- Mogu direktno opažati samo površinsku temperaturu.

Sva tijela iznad apsolutne nule emitiraju infracrveno zračenje. Stoga je dobar način za mjerenje toplinskih varijacija korištenje uređaja za infracrveno viđenje. Kod pasivne termografije, dijelovi koji nas zanimaju su prirodno na višoj ili nižoj temperaturi od pozadine. Pasivna termografija ima mnoge primjene, kao što su nadzor ljudi i medicinska dijagnoza. Aktivnoj je termografiji, s druge strane, potreban energetski izvor da bi se napravio termalni kontrast između predmeta promatranja i pozadine. Aktivni je pristup potreban u mnogim slučajevima kad su predmeti promatranja u ravnoteži s okolinom [6]. 


\subsection{Osnovne karakteristike IC kamere}

Za mjerenja opisana u ovome radu korištena je FLIR i7 termalna kamera (slika 2), s tehničkim karakteristikama prikazanim u tabeli 2.

Tabela 2 - FLIR i7 termalna kamera

\begin{tabular}{|c|c|c|}
\hline Točnost & $+/-2 \%$ & \\
\hline Osjetljivost & $<0,1^{\circ} \mathrm{C} \operatorname{kod} 25^{\circ} \mathrm{C}$ & \\
\hline Vidno polje & $25^{\circ} \times 25^{\circ} / 0,6 \mathrm{~m}$ & $y$ \\
\hline Detektor & $\begin{array}{c}\text { FPA } 120 \times 120 \text { piksela } \\
\text { (nehlađeni mikrobolometar) }\end{array}$ & \\
\hline Područje osjetljivosti & $7,5-13$ mikrona & \\
\hline Monitor & kolor LCD 2,8“" & \\
\hline Spremanje slike & u realnom vremenu, 5000 slika & \\
\hline Masa & $0,34 \mathrm{~kg}$ & \\
\hline Temperaturna mjerna područja & $0^{\circ} \mathrm{C}-250^{\circ} \mathrm{C}$ & Slika 2 - FLIR i7 termalna kamera \\
\hline
\end{tabular}

\section{Primjena termografije u građevinarstvu}

Veliki dio ukupne potrošnje energije otpada na ostvarivanje toplinskog komfora u zgradama. Infracrvena termografija pokazala se kao izuzetno korisna metoda za vizualizaciju toplinskih gubitaka kroz elemente konstrukcije kod istraživanja potencijala povećanja energetske učinkovitosti zgrada (slika 3).Termografskim snimanjem zgrada, te kasnijom stručnom interpretacijom, moguće je locirati nedostatke konstrukcije i usmjeriti zahvate na sanaciji prema optimalnom poboljšanju energetske učinkovitosti sustava zgrade [6].

Nedostatci u konstrukciji koji se mogu ustanoviti termografskim snimanjem su: nehomogenost materijala zida, neispravnost ili nepostojanje toplinske izolacije, vlaga u konstrukciji, problemi ravnih krovova, toplinski mostovi, otvoreni propusti za zrak-ventilaciju, fuge i slično, kao i koncentracija instalacija u zidu [7]. Osim toga, infracrvenom termografijom moguće je detektirati havarije ili manja propuštanja sustava u smislu procurivanja instalacija ugrađenih u zidove i/ili energetske kanale, ali također i eventualne nedostatke i oštećenja izolacije ugrađenih instalacija koja se ne mogu ustanoviti običnim vizualnim pregledom sustava. Pomoću termografskih snimaka dijelova konstrukcije moguće je vrlo brzo prepoznati nedostatke povezane s toplinskim karakteristikama, otkriti uzroke i predložiti sanaciju. Za pravilno snimanje IC termograma, a naročito za njihovu interpretaciju, potrebno je educirano i certificirano osoblje.

\subsection{Energetska bilanca zgrade}

Potrebna količina energije u kući ili zgradi ovisi o obliku zgrade, orijentaciji, sastavu konstrukcije i nivou toplinske izolacije vanjske ovojnice zgrade, te o klimatskim uvjetima. Prosječne stare kuće godišnje troše $200-280 \mathrm{kWh} / \mathrm{m}^{2}$ energije za grijanje, standardno izolirane kuće ispod 100, suvremene niskoenergetske kuće oko 40, a pasivne 15 $\mathrm{kWh} / \mathrm{m}^{2}$ i manje. Prema iskustvima koja je Centar za razvoj i podršku (CRP) stekao obavljajući energetske preglede i proračune mnogobrojnih objekata, u zgradama u Bosni i Hercegovini troši se više od $200 \mathrm{KWh} / \mathrm{m}^{2}$ energije godišnje, dok se kod privatnih kuća ti pokazatelji kreću oko $350 \mathrm{KWh} / \mathrm{m}^{2}$ godišnje. CRP procjenjuje da je, uz primjenu mjera energetske učinkovitosti, potencijal smanjenja troškova za energiju preko $30 \%$ iznosa budžeta svih institucija u našoj zemlji $[2,3,4]$.

Podatak koji se koristi za proračune, a ovisi o klimatskim uvjetima, je stupanj - dan grijanja, odnosno produkt broja dana grijanja i razlike između prosječne unutrašnje i vanjske temperature. Drugi bitan podatak koji se koristi kod proračuna količine energije za grijanje je koeficijent prolaska topline kroz vanjski građevni dio zgrade, tzv. U(k) faktor. Toplinski gubtici kroz građevinski element, između ostalog, ovise o sastavu građevinskog 
elementa, orijentaciji i koeficijentu toplinske provodljivosti ugrađenih materijala. Bolju toplinsku izolaciju postižemo ugradnjom materijala niske toplinske provodljivosti, odnosno visokog toplinskog otpora. Poboljšanjem toplinskoizolacijskih karakteristika zgrade moguće je postići smanjenje ukupnih gubitaka topline građevine prosječno za $50-80 \%$.
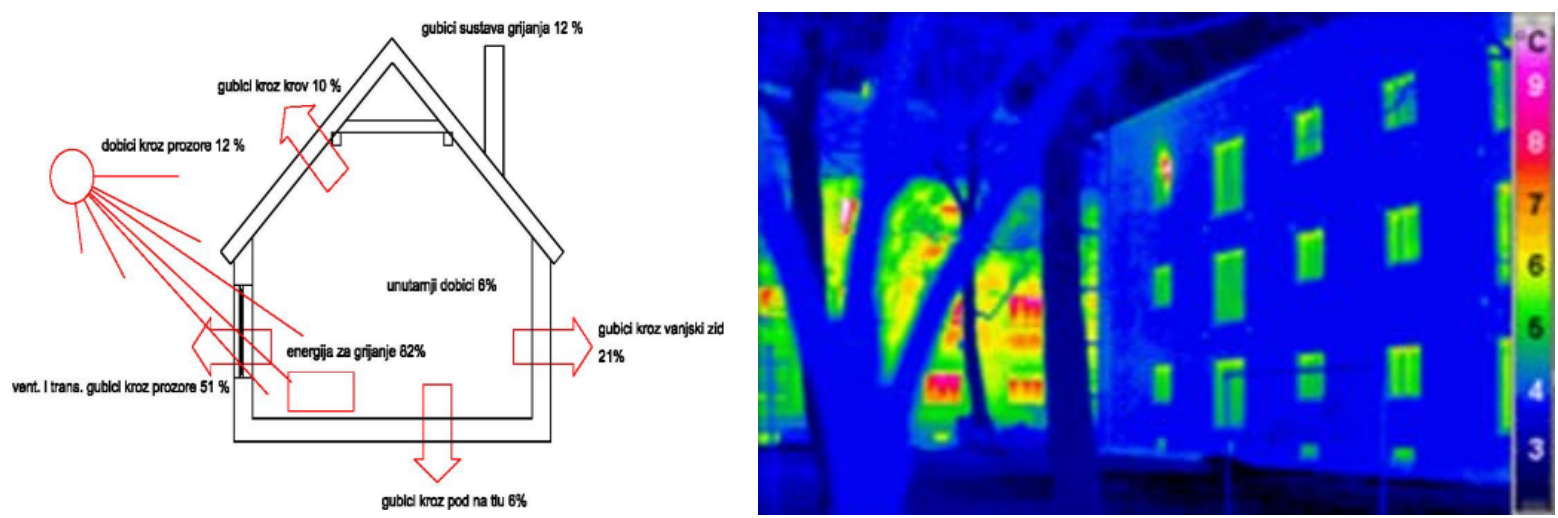

Slika 3 - Energetska bilanca zgrade i primjer termograma tradicionalne zgrade (u pozadini) i pasivna kuća (ispred). Termogrami su snimljeni pri ambijentalnoj temperaturi od $4^{\circ} \mathrm{C}$.

Ukupna energetska bilanca zgrade uključuje: transmisijske toplinske gubitke i toplinske gubitke zbog provjetravanja, iskoristive unutrašnje toplinske dobitke, iskoristive toplinske dobitke od Sunca, toplinske gubitke u sustavu grijanja i energiju dovedenu u sustav grijanja. Prozori i vanjski zid igraju veliku ulogu u toplinskim gubitcima zgrade, jer zajedno čine preko $70 \%$ ukupnih toplinskih gubitaka kroz ovojnicu zgrade [3].

\subsection{Prednosti i uštede prilikom energetski učinkovite gradnje}

Suvremeno građevinarstvo podrazumijeva primjenu standarda energetske učinkovitosti, i to kako kod rekonstrukcije postojećih, tako i kod izgradnje novih zgrada. To podrazumijeva osiguravanje uvjeta za smanjenje emisije ugljikovog dioksida, uz očuvanje postojećih standarda kvalitete gradnje i stanovanja [8]. Energetski osviješteno građevinarstvo ima svrhu smanjiti gubitke topline iz zgrade poboljšanjem toplinske izolacije vanjskih elemenata i povoljnim odnosom opsega i volumena zgrade, povećati toplinske dobitke u zgradi orijentacijom zgrade i korištenjem Sunčeve energije, koristiti obnovljive izvore energije, te povećati energetsku učinkovitost sustava grijanja i hlađenja.

Za krajnjeg korisnika, naravno, najveća je korist u smanjenju računa za grijanje, hlađenje i električnu energiju. Cijene energije i energenata će, zbog globalnih i lokalnih razloga, u idućem razdoblju i dalje rasti - što će utjecati na porast troškova života i stanovanja [4]. Direktna korist od energetski učinkovite gradnje ogleda se u:

- financijskim uštedama na smanjenim računima za grijanje, hlađenje i električnu energiju;

- ugodnijem i kvalitetnijem stanovanju, te dužem životnom vijeku zgrade;

- doprinosu zaštiti okoliša i smanjenju emisija štetnih plinova u okoliš, kao i globalnim klimatskim promjenama.

\section{Primjeri primjene ICT mjerenja u kontroli energetske učinkovitosti zgrada}

Opće mjere poticanja energetske učinkovitosti korištenja obnovljivih izvora energije obuhvaćaju istraživačke, obrazovne i promotivne mjere koje imaju veliku društvenu korist, a teško ih je financijski i ekonomski valorizirati. Dakle, u ovom području potrebno je poticati sve informativne, obrazovne i promotivne aktivnosti radi uklanjanja barijera implementaciji mjera energetske učinkovitosti i korištenja obnovljivih izvora energije [3].

S primjenom ICT-a u građevinarstvu započelo se već od druge polovine 60-ih godina, ali od druge polovine 90-ih godina prošlog stoljeća znatno se povećala primjena termografije. Zgrade mogu imati probleme uzrokovane neadekvatnim projektom, konstrukcijom i održavanjem koje je teško dijagnosticirati i riješiti. Glavni problemi koji se pojavljuju u građevini, a u rješavanju kojih se koristi ICT, jesu [7]: 
- pretjerana uporaba energije zbog nedostatka ili oštećenja izolacija, izolacija koja je izvedena neadekvatno i pretjeranog istjecanja zraka iz zgrade

- oštećenja od kvašenja zbog prodora ili kondenzacije vodene pare, posebno zidova i krovova

- raspodjela grijaćih tijela koja nije optimalna i nezadovoljavajuće osobine sistema grijanja - hlađenja ventilacije

- nedovoljna potvrda valjanosti detalja konstrukcije ili strukturnih karakteristika

- raslojavanje materijala pročelja

- sindromi "bolesne zgrade", rast gljivica i druge, sa zdravljem povezane pojave

- oštećenja krovova.

Problemi se često, kao i njhovi uzroci i posljedice, ne mogu vidjeti dok ne nastanu ozbiljne štete. Tada je jedino rješenje skupa rekonstrukcija. Velika je vrijednost ICT-a što omogućava vidljivost oku nevidljivih toplotnih pokazatelja povezanih s mnogima od navedenih problema u zgradama. Kada se ispravno koristi, termografija omogućava vlasnicima zgrada, arhitektima, korisnicima i inspektorima (nadzornicima) da lociraju probleme, provjere karakteristike zgrade i potvrde rješenja.

Studenti Rudarsko-geološko-građevinskog fakulteta Tuzla susreću se s pojmom termografije kroz nekoliko nastavnih predmeta (Termodinamika, Energetski resursi i energetika, Energetska efikasnost itd.).

\subsection{Rezultati i rasprava}

U ovome radu pokazane su dvije vježbe u kojima je zadatak bio pronaći i snimiti zgrade s djelomično napravljenom toplinskom izolacijom, tako da bi se na primjeru konstrukcijski iste zgrade mogla uočiti razlika u energetskoj učinkovitosti toplinski izoliranog od toplinski neizoliranog dijela zgrade, pri istim uvjetima zagrijavanja prostorija centralnim sustavom grijanja. Na narednim slikama $(4,5)$ prikazana su dva pronađena slučaja, u kojima je u zgradama s 4 stana samo jedan stan toplinski izoliran na vanjskim zidovima, dok je ostatak zgrade bez izolacije.

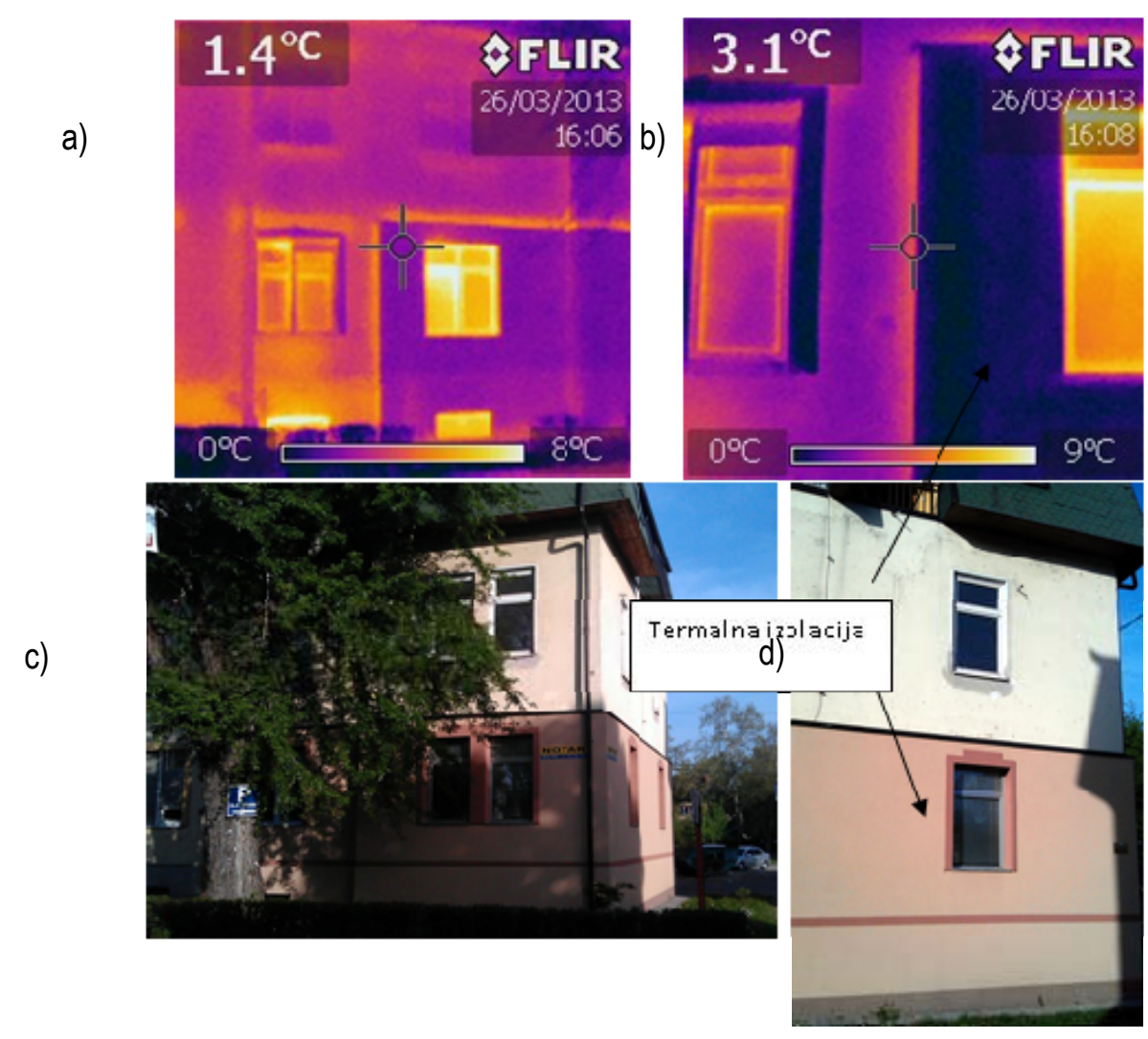

Slika 4 - Razlika u temperaturama vanjske površine zida s toplinskom izolacijom i bez izolacije, primjer 1; slike pod a) i b) predstavljaju isti objekt kao slike pod c) i d) gledan kroz IC kameru 
a)

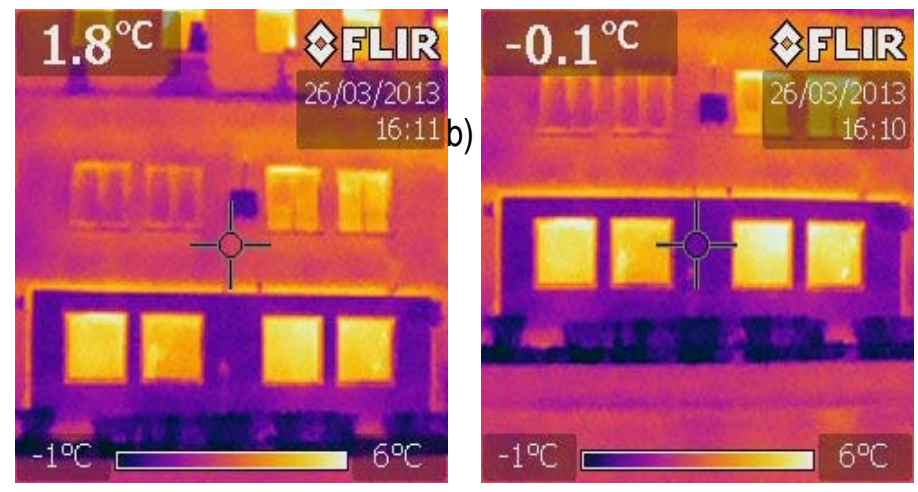

c)

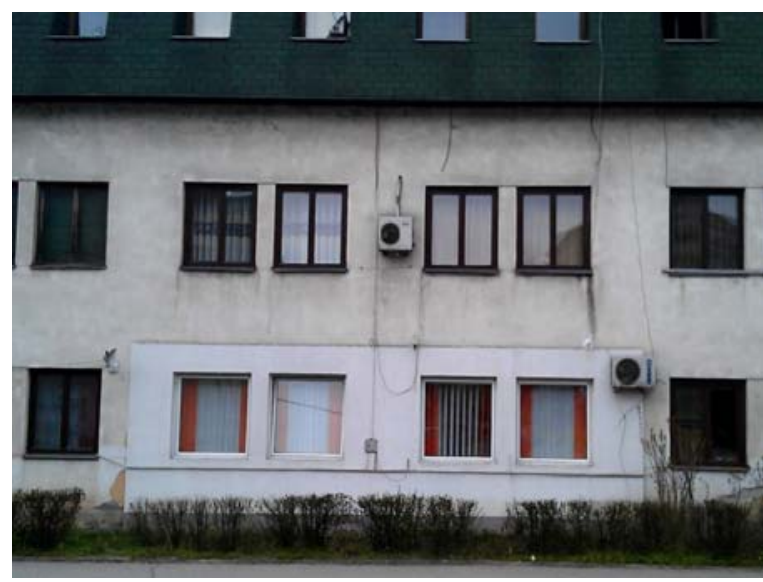

Slika 5 - Razlika u temperaturama vanjske površine zida s toplinskom izolacijom i bez izolacije, primjer 2; slike pod a) i b) predstavljaju isti objekt prikazan na slici c) gledan kroz IC kameru

U ovakvim slučajevima niža temperatura površine vanjskog zida indicira bolju toplinsku izolaciju (naravno, ako se unutrašnjost zgrade zagrijava), odnosno manji gubitak toplinske energije. $U$ drugom primjeru mjerenja izoliran je samo jedan vanjski zid stambene jedinice kojoj je to ujedno i jedina površina putem koje može ostvariti gubitak toplinske energije (ostali zidovi su unutrašnji, prema ostalim stanovima u stambenoj zgradi). IC fotografije pokazuju razliku od $1,9^{\circ} \mathrm{C}$ između toplinski izoliranog I neizoliranog zida iste zgrade.

\section{Pravilnik ICT mjerenja}

Radi moguće krive interpretacije IC fotografija, što je često posljedica utjecaja vanjskih faktora i načina provedbe mjerenja, značajno je postupanje prema određenim normama i dobroj laboratorijskoj praksi. Norme koje se odnose na ICT pri primjeni u građevinarstvu su s kraja prošlog, odnosno početka ovog stoljeća, a to su [9]:

- ASTM C1060-90(2003) „Standard Practice for Thermographic Inspection of Insulation Installations in Envelope Cavities of Frame Buildings"

- ASTM C1153-97(2003)e1 "Standard Practice for Location of Wet Insulation in Roofing Systems Using Infrared Imaging"

- ASTM D4788-03 „Standard Test Method for Detecting Delaminations in Bridge Decks Using Infrared Thermography"

- ASTM E1186-03 „Standard Practices for Air Leakage Site Detection in Building Envelopes and Air Barrier Systems"

- EN 13187:1998 „Thermal performance of buildings - Qualitative detection of thermal irregularities in building envelopes - Infrared method"

- EN ISO 9712:2012 Non-destructive testing - Qualification and certification of NDT personnel. 


\section{Zaključci}

U Bosni i Hercegovini u primjeni ne postoje propisi, a ni određena laboratorijska praksa za ICT mjerenja. Kako su u posljednje vrijeme znatno pojeftinili termografski uređaji, uporaba ICT-a brzo se povećava, a time i broj osoba koje obavljaju termografska mjerenja. Dakle, za optimalnu korist od ICT-a nužna je primjena normi i postupanja sukladno postupanju u državama u kojima je to područje uređeno. Potrebno je svakako zadovoljiti određene nužne uvjete za uspješnu provedbu ICT mjerenja i analize termograma. Edukacija u ovom području je svakako prvi korak ka upješnom prihvaćanju i pravilnoj implementaciji IC termografije u svim područjima njezine moguće primjene. Jedno od veoma interesantnih i dosada malo zastupljenih područja primjene je otkrivanje ranih faza spontanog zagrijavanja ugljenog sloja i endogenih požara u podzemnim rudnicima uglja [1]. U ovome radu prikazan je samo jedan segment primjene IC termografije u području energetske učinkovitosti koji je u ovom trenutku vjerojatno i najzastupljeniji. Ovo je posljedica dostupnosti i relativno niskih cijena pouzdanih IC kamera s jedne strane, te potreba i preporuka koje se tiču energetske učinkovitosti javnih i stambenih zgrada, s druge. Međutim, u BiH se trenutačno IC termografija koristi uglavnom za ocjenu učinkovitosti toplinske izolacije vanjskih zidova objekata, a tek sporadično tijekom projektiranja, ispitivanja konstrukcija i drugih područja primjene navedenih u poglavlju 4.

\section{Literatura}

[1] Delić, E.; Savatić, A.; Todorović, N.; Šišić, R.; Nukić, E.: "Termografska detekcija spontane oksidacije u podzemnim rudnicima uglja", VIII konferencija QUALITY 2013, juni 2013.

[2] www.energetska-efikasnost.ba, Privredna komora Kantona Sarajevo - Centar za energetsku efikasnost

[3] Vodič za energetski efikasnu gradnju, Privredna komora Kantona Sarajevo, EU projekat Razvoj i unapređenje konkurentnosti malih i srednjih preduzeća na polju povećanja energetske efikasnosti, Sarajevo, 2008.

[4] http://zastitaokolisa.crp.org.ba

[5] Švaić, S.; Boras, I.: "Infracrvena tomografija", dodiplomski studij, laboratorijski rad, str.7-9 V.

[6] Pašagić: "Primjena termografije u građevinarstvu", 24.04.2008., str. 1061

[7] Borković, Ž.H.; Suša, M.: "Primjena IC termografije u zgradarstvu"

[8] Marković, D.: "Procesna i energetska efikasnost", autorizovana predavanja, 2009-2010

[9] American Society for Testing and Materials (www.astm.org) 